\title{
ОСОБЕННОСТИ КЛИНИЧЕСКОГО ТЕЧЕНИЯ ОСЛОЖНЕННЫХ ФОРМ МИГРЕНИ ПО РЕЗУЛЬТАТАМ ОПРОСНИКА ID- MIGRAINE
}

Гулова Мунисахон

Магистр 2-степени, Бухарский государственньй медицинский институт, 200100, Узбекистан, г.Бухара, ул проспект А. Наваи-1

Саноева Матлюба

к.м.н., доцент, Бухарский государственный медицинский институт, 200100, Узбекистан, г.Бухара, ул проспект А. Наваи-1

Саидвалиев Фарруг

д.м.н., профессор, Ташкентская медиииская академия, Узбекистан,

г.Ташкент, ул.Фаробий-2

\section{Аннотация}

В работе приведен сравнительный анализ клинической картины некоторых осложненных форм мигрени с неосложненными её формами по опроснику IDmigraine и показана количественная их разница; исследован психологический статус пациентов с осложненной мигренью по шкалам депрессии $u$ тревожности Гамильтона. Доказано превалирование депрессивно-тревожных состояний у больных с осложненными формами мигрени и зависимость их выраженности от наличия ауры. Основываясь полученным клиническим данным приведены некоторые критерии дифференциильной диагностики осложненных и неосложненных форм мигрени.

\section{Abstract}

The research presents a comparative analysis of the clinical picture of some complicated forms of migraine with its uncomplicated forms according to the IDmigraine questionnaire and shows their possible quantitative difference; the psychological status of patients with complicated migraine according to the scales of depression and anxiety of Hamilton. The prevalence of depression and anxiety in patients with complicated forms of migraine and the dependence of their severity on the presence of aura have been proved. Based on the obtained clinical data, some criteria 
for the differential diagnosis of complicated and uncomplicated forms of migraine are presented.

Ключевые слова: мигрень, осложненная мигрень, мигренозный статус, хроническая мигрень, ID-migraine, шкалы депрессии и тревожности Гамильтона

Key words: migraine, complicated forms of migraine, migraine status, chronic migraine, scales of depression and anxiety of Hamilton

Актуальность. Хроническая и эпизодическая головная боль (ГБ) является одной из немаловажных причин развития психоэмоциональных нарушений [7] и социальной дезадаптации лиц молодого возраста. Практически для $20 \%$ населения ГБ становится серьезной проблемой, снижающей качество жизни и трудоспособность [1], вне зависимости от их возраста, пола и расы. Так, в США по данным специальных опросов обнаружено снижение качества жизни у 18,8 млн. женщин и 2,7 млн. мужчин, страдающих мигренью [5]. В международной классификации головной боли (МКГБ-3) различается первичная головная боль, как самостоятельное заболевание, и вторичная ГБ, представляющая собой проявление различных неврологических, соматических, системных и других заболеваний.

Явным представителем первичных головных болей является мигрень хроническое заболевание, распространённое в популяции до $10 \%$ диагностированных, и ещё $5 \%$ не диагностированных или неверно диагностированных больных $[3,6]$. Мигрень чаще всего встречается у женщин, так как передается, в основном, по женской линии, однако, нередко и у мужчин, с частотой 2,5:1 [2]. Тяжесть заболевания варьирует от редких (несколько раз в год), сравнительно лёгких приступов, до ежедневных, но, чаще всего, приступы мигрени повторяются с периодичностью 2-8 раз в месяц [4]. Периодическая или непредсказуемая потеря работоспособности во время приступов мигрени, снижение качества жизни, интерес широкого круга врачей, и не только неврологов, частая, ошибочная диагностика, развитие осложненных форм мигрени стали поводом для изучения данной проблемы. 
В связи со сказанным целью нашего исследования стало анализировать клиническую картину осложненных форм мигрени в сравнительном аспекте, используя опросник ID-migraine, и оптимизировать критерии диагностики для изучаемых её вариантов.

Материал и методы исследования. Провели сравнительный анализ 239 (100\%) больных с различными вариантами течения мигрени. Для этого выбрали основную группу больных с мигренозным статусом 78 (32,6\%) и хронической мигренью 82 (34,3\%) обследрванных, а также как контрольную группу рассматривали - 78 (20,6\%) пациентов с неосложненными мигренями (НОМ). Проведен тщательный сбор субъективных и объективных неврологических данных, анамнеза заболевания с изучением характера мигренозных приступов. При оценке субъективных данных использовали опросник ID-migraine, состоящую из триады симптомов и исследование психоэмоционального состояния, используя шкалы депрессии и тревожности Гамильтона (HDRS-21, HAM-A).

Результаты исследования. Мигренозные приступы при мигренозном статусе длились до 3-3,5 суток, общее состояние часто оказывалось тяжелым. При хронической мигрени приступ продолжался до 24 суток, общее состояние больных варьировало в течение всего приступа от тяжелого до относительно удовлетворительного. Среди больных с мигренозным статусом 17 (21,8\%) страдали с «Мигрень с аурой» (МА) и у 61 (78,2\%) заболевание протекало без ауры, как обычная мигрень (МО); при хронической мигрени МА наблюдалась у 26 (31,7\%) обследуемых, МО у 56 (68,3\%); при НОМ количество больных с МА оказалось 18 (22,8\%) и МО 61 (77,2\%) обследованных. Как показал анализ при наличии МА, не зависимо от варианта течения осложненной и/или НОМ клиника мигрени протекала тяжелее по сравнению с МО. Мигренозные пароксизмы удлинялись, очаговые неврологические симптомы, выявляемые во время мигренозного приступа при осложненных мигренях задерживались даже после прекращения ГБ в течение нескольких дней, ухудшался эмоциональный и когнитивный фон. 
У больных с мигренозным статусом по данным опросника ID-migraine рвота наблюдалась у 62 (79,5\%) пациентов и у 34 (43,6\%) она приносила временное облегчение, другие пациенты не смотря на искусственно вызванную рвоту улучшения состояния не отмечали; пропадал аппетит, наблюдалась гиперосмия на запахи (еды, пряностей и парфюмерных изделий). Больные из-за непереносимости света и звука становились тревожными, возбужденными, а сами ГБ превращали эмоциональный фон в агрессивность, пациенты находили повод для споров и скандалов, данное состояние держалось до 7 дней после ремиссии приступов. Также отмечали вялость, чувство тяжести и усталости всего тела, сонливость в течение до 3-х суток.

Приводим анализ опросника ID-migraine в сравнительном аспекте между различными вариантами течения осложненных форм мигрени (таблица 1):

Таблица 1

\section{Клинические признаки мигрени по опроснику}

ID-migraine в сравнительном аспекте

\begin{tabular}{|c|c|c|c|c|c|c|}
\hline \multirow{2}{*}{$\begin{array}{c}\text { Клинические } \\
\text { признаки }\end{array}$} & \multicolumn{2}{|c|}{$\begin{array}{c}\text { Мигренозный статус } \\
(\mathrm{n}=78)\end{array}$} & \multicolumn{2}{|c|}{$\begin{array}{c}\text { Хроническая мигрень } \\
(\mathrm{n}=82)\end{array}$} & \multicolumn{2}{c|}{$\begin{array}{c}\text { Неосложненная } \\
\text { мигрень }(\mathrm{n}=79)\end{array}$} \\
\cline { 2 - 7 } & $\mathrm{MA}$ & $\begin{array}{c}\text { MO } \\
\mathrm{n}=61(\%)\end{array}$ & $\begin{array}{c}\text { MА } \\
\mathrm{n}=26(\%)\end{array}$ & $\begin{array}{c}\text { MO } \\
\mathrm{n}=56(\%)\end{array}$ & $\mathrm{n}=18(\%)$ & $\mathrm{n}=51(\%)$ \\
\hline Тошнота & 88,2 & 78,7 & 96,2 & 91,1 & 77,8 & 66,7 \\
\hline Рвота & 82,4 & 82,0 & 69,2 & 67,9 & 72,2 & 46,4 \\
\hline Фотофобия & 70,6 & 60,6 & 53,9 & 41,1 & 55,6 & 39,2 \\
\hline Фонофобия & 88,2 & 75,4 & 88,5 & 85,7 & 83,3 & 74,5 \\
\hline $\begin{array}{c}\text { Сниж.повседн } \\
\text { евактивности }\end{array}$ & 94,1 & 93,4 & 96,2 & 94,6 & 88,9 & 86,3 \\
\hline
\end{tabular}

Как видно, рвота чаще наблюдалась у больных с мигренозным статусом, при чем она была в основном многократной в отличие от групп хронической мигрени и НОМ $(\mathrm{p}<0,05)$. Тошнота была более характерной для группы больных с хронической мигренью, но статистически достоверной разницы между мигренозным статусом не отмечали. В отличие от мигренозного статуса при хронической мигрени рвота не приносила облегчения и переносилась хуже, вместе с затяжными приступами ГБ. При наличии ауры перечисленные симптомы 
выявлялись относительно часто, чем при МО, но статистической разницы между ними не выявили.

У больных в основной группе как при МА, так и при МО изменения в эмоциональной сфере были практически одинаковыми, в отличие от больных с HOM (p<0,05). Пациенты непосредственно перед и во время приступов мигрени становились капризными, агрессивными, апатичными, уединялись в свой уголок, старались находится в бесшумном, темном помещении никого не подпуская к себе, отказывались от пищи, разговоров, которая могла длится до 3-5 дней после ремиссии. Кроме этого, отмечалось снижение работоспособности, повседневной активности, отказ от посещения мероприятий, дел, школ у детей у 92,5\% пациентов среди основной группы и у 58,2\% из сравнительной группы с НОМ $(\mathrm{p}<0,05)$. Как и при мигренозном статусе у обследованных больных с хронической мигренью наблюдалась гиперосмия на запахи, которые усиливали тошноту с рвотой, продолжительные приступы ГБ вызывали тяжесть в голове и затуманенность.

Опросник ID-migraine превратился в дневник для обследуемых, который помогал дифференцировать мигрень от других видов головных болей, давал возможность выявить качественные характеристики симптомов между осложненными и неосложненными вариантами, а также сопоставлять характер симптомов между МА и МО. Изменения в эмоциональной сфере стали поводом для изучения психопатологического состояния больных с осложненными формами мигрени в сравнительном аспекте с НОМ. Обследованные больные с мигренью показали высокую предрасположенность к дистрессам и тревожнодепрессивным состояниям. Согласно шкале HDRS-21 при мигренозном статусе была выявлена тенденция к развитию депрессии у 28 (35,9 \%) пациентов (таблица 2). При сравнении МА и МО отмечалось наибольшее количество больных с депрессией у пациентов при мигрени с аурой, но данная разница оказалась статистически не достоверной.

Таблица 2

Степень тяжести депрессии у больных с мигренозным статусом (n=28) 


\begin{tabular}{|c|c|c|c|c|c|c|}
\hline \multirow{2}{*}{ Возраст } & \multicolumn{6}{|c|}{ Степени выраженности депрессии } \\
\cline { 2 - 7 } больных & \multicolumn{2}{|c|}{ Легкая степень } & \multicolumn{2}{c|}{ Средняя степень } & \multicolumn{2}{|c|}{ Тяжелая степень } \\
\cline { 2 - 7 } & Абс & $\%$ & Абс & $\%$ & Абс & $\%$ \\
\hline Общ.кол-во & 7 & 25,0 & 13 & 46,4 & 8 & 28,6 \\
\hline Детский & 3 & 10,7 & - & - & - & - \\
\hline Молодой & 4 & 14,3 & 8 & 28,6 & 5 & 17,9 \\
\hline Средний & - & - & 5 & 17,9 & 3 & 10,7 \\
\hline
\end{tabular}

Как видно из анализируемого, при сравнении изменений по возрастным группам, выявили среднюю и тяжелую степень депрессии в основном у молодых и пациентов среднего возраста. У женщин в общей сложности депрессия встречалась в 2 раза больше, чем у мужчин $(\mathrm{p}<0,05)$.

По шкале НАМ-А тревожное расстройство выявили у более половины больных с мигренозным статусом, составляя 47 (60,3 \%) обследованных. Оно проявлялось гиперактивностью, непоседливостью, беспокойной походкой, различными тревожными и навязчивыми мыслями (неизлечимость заболевания, назойливый расспрос каждого сказанного слова и назначаемого лечения). Распределение выраженности тревоги по возрасту показаны в таблице 3.

Таблица 3

Степень тяжести тревоги у больных с мигренозным статусом (n=47)

\begin{tabular}{|c|c|c|c|c|c|c|c|c|}
\hline \multirow{3}{*}{$\begin{array}{l}\text { Возраст } \\
\text { больных }\end{array}$} & \multicolumn{6}{|c|}{ Степени выраженности тревоги } & & \\
\hline & \multicolumn{2}{|c|}{$\begin{array}{c}\text { Возможная } \\
\text { тревога }\end{array}$} & \multicolumn{2}{|c|}{ Тревога } & \multicolumn{2}{|c|}{$\begin{array}{c}\text { Симптоматичес } \\
\text { кая тревога }\end{array}$} & \multicolumn{2}{|c|}{$\begin{array}{c}\text { Выраженная } \\
\text { тревога }\end{array}$} \\
\hline & абс & $\%$ & Абс & $\%$ & абс & $\%$ & Абс & $\%$ \\
\hline Общ.кол. & 17 & 36,2 & 19 & 40,4 & 8 & 28,6 & 3 & 6,4 \\
\hline Детский & 2 & 4,3 & 3 & 6,4 & - & - & - & - \\
\hline Молодой & 10 & 21,3 & 14 & 30,0 & 5 & 17,9 & 3 & 6,4 \\
\hline Средний & 5 & 10,6 & 2 & 4,3 & 3 & 10,7 & - & - \\
\hline
\end{tabular}

Сравнивая выявили, что при мигренозном статусе тревожные расстройства встречались в 1,7 раза чаще при МА, чем при МО. Превалирование тяжелой степени депрессии и тревожного состояния у молодых было связано с интенсивностью ГБ.

Анализируя группу больных с хронической мигренью согласно шкале HDRS-21 у 61 (74,4 \%) больного выявили депрессию (таблица 4) 
Степень тяжести депрессии у больных с хронической мигренью (n=61)

\begin{tabular}{|c|c|c|c|c|c|c|}
\hline \multirow{2}{*}{ Возраст } & \multicolumn{6}{|c|}{ Степени выраженности депрессии } \\
\cline { 2 - 7 } больных & \multicolumn{2}{|c|}{ Легкая степень } & \multicolumn{2}{|c|}{ Средняя степень } & Тяжелая степень \\
\cline { 2 - 7 } & Абс & $\%$ & Абс & $\%$ & Абс & $\%$ \\
\hline Общ.кол-во & 12 & 19,7 & 34 & 55,7 & 15 & 24,6 \\
\hline Детский & 3 & 4,9 & - & - & - & - \\
\hline Молодой & 6 & 9,8 & 26 & 42,6 & 13 & 21,3 \\
\hline Средний & 3 & 4,9 & 8 & 13,1 & 2 & 3,3 \\
\hline
\end{tabular}

По гендерному признаку различная степень депрессии встречалась в 2,3 раза чаще у женщин, чем у мужчин $(\mathrm{p}<0,01)$, что подчеркивало большую подверженность женщин к дистрессу и психопатологическому состоянию при мигренях. Признаки депрессии такие как апатия, уединенность, тенденция к подавленности настроения, избегание общественных мест и большого количества людей, игнорирование мероприятий и веселья проявлялись практически одинаково, как и при мигренозном статусе, отличался лишь симптом плаксивости, которая при хронической мигрени наблюдался в 2 раза чаще и проявлялась при малейших эмоциях $(\mathrm{p}<0,05)$. По частоте депрессия наблюдалась в 2,1 раза чаще при хронической мигрени по сравнению с мигренозным статусом $(\mathrm{p}<0,05)$. При МА у больных с хронической мигренью депрессия превалировала в 1,3 раза, чем при МО. Как показано в таблице 4 средняя и тяжелая степень депрессии при хронической мигрени превалировали над легкой степенью $(\mathrm{p}<0,05)$.

Исследуя наличие тревоги при хронической мигрени по шкале НАМ-А тревожное расстройство наблюдалось у 48 (58,5 \%) пациентов. Не смотря на отсутствие статистического различия между количеством пациентов с тревогой при хронической мигрени и мигренозным статусом, степень проявления тревожных расстройств достоверно отличались (таблица 5).

Таблица 5

Степень тяжести тревоги у больных с хронической мигренью $(\mathrm{n}=48)$

\begin{tabular}{|c|c|c|c|c|c|c|c|c|}
\hline \multirow{3}{*}{$\begin{array}{l}\text { Возраст } \\
\text { больных }\end{array}$} & \multicolumn{8}{|c|}{ Степени выраженности тревоги } \\
\hline & \multicolumn{2}{|c|}{$\begin{array}{c}\text { Возможная } \\
\text { тревога }\end{array}$} & \multicolumn{2}{|c|}{ Тревога } & \multicolumn{2}{|c|}{$\begin{array}{c}\text { Симптоматиче } \\
\text { ская тревога }\end{array}$} & \multicolumn{2}{|c|}{$\begin{array}{c}\text { Выраженная } \\
\text { тревога }\end{array}$} \\
\hline & абс & $\%$ & Абс & $\%$ & Абс & $\%$ & Абс & $\%$ \\
\hline Общ.кол. & 8 & 16,7 & 22 & 45,8 & 13 & 27,1 & 5 & 10,4 \\
\hline
\end{tabular}




\begin{tabular}{|c|c|c|c|c|c|c|c|c|}
\hline Детский & 1 & 2,1 & - & - & - & - & - & - \\
\hline Молодой & 6 & 12,5 & 18 & 37,5 & 13 & 27,1 & 2 & 4,2 \\
\hline Средний & 1 & 2,1 & 4 & 8,3 & - & - & 3 & 6,3 \\
\hline
\end{tabular}

Так, из таблица 5 видно, что возможная тревога в 2,2 раз чаще встречалась при мигренозном статусе, тревога практически не имела статистической разницы, симптоматическая тревога в 1,4, а выраженная тревога в 2,4 раза превышала при хронической мигрени.

Исследование продолжили, сопоставляя психопатологическое состояние основной группы с группой сравнения. Согласно шкале HDRS-21 при HOM (сравнительная группа) у 27 (34,2\%) пациентов обнаружили признаки депрессии, что было статистически одинаково с количеством больных с мигренозным статусом, страдающих депрессией и в 2,2 раза меньше, чем при хронической мигрени (таблица 6).

Таблица 6

\section{Степень тяжести депрессии у больных с неосложненной мигренью} $(n=27)$

\begin{tabular}{|c|c|c|c|c|c|c|}
\hline \multirow{2}{*}{$\begin{array}{c}\text { Возраст } \\
\text { больных }\end{array}$} & \multicolumn{6}{|c|}{ Степени выраженности депрессии } \\
\cline { 2 - 7 } & Легкая степень & \multicolumn{2}{c|}{ Средняя степень } & Тяжелая степень \\
\cline { 2 - 7 } & Абс & $\%$ & Абс & $\%$ & Абс & $\%$ \\
\hline Общ.кол-во & 11 & 40,7 & 16 & 59,3 & - & - \\
\hline Детский & - & - & 2 & 7,4 & - & - \\
\hline Молодой & 6 & 22,2 & 14 & 51,9 & - & - \\
\hline Средний & 5 & 18,8 & - & - & - & - \\
\hline
\end{tabular}

Как видно из таблицы 6, при НОМ легкая степень депрессии превышала в 1,6 раза, чем при мигренозном статусе $(\mathrm{p}<0,01)$ и в 2,2 раза, чем при хронической мигрени $(\mathrm{p}<0,05)$. У молодых легкая депрессия встречалась в 2,3 раза чаще, чем при хронической мигрени $(\mathrm{p}<0,05)$ и в 2,1 раза чаще, чем при мигренозном статусе $(p<0,05)$. Средняя степень депрессии встречалась практически одинаково с хронической мигренью и в 1,3 раза чаще, по сравнению с мигренозным статусом. В отличие от сравнительной группы при осложненных формах наблюдалась в основном тяжелая степень депрессивных расстройств. 
По шкале НАМ-А у 23 (29,1 \%) выявили тревожное состояние, которое по сравнению с основной оказалось в 2 раза реже (таблица 7).

Таблица 7

Степень тяжести тревоги у больных с неосложненной мигренью $(\mathrm{n}=23)$

\begin{tabular}{|c|c|c|c|c|c|c|c|c|}
\hline \multirow{2}{*}{$\begin{array}{c}\text { Возраст } \\
\text { больных }\end{array}$} & \multicolumn{9}{|c|}{$\begin{array}{c}\text { Возможная } \\
\text { тревога }\end{array}$} & \multicolumn{2}{|c|}{ Тревога } & \multicolumn{2}{c|}{$\begin{array}{c}\text { Симптоматическ } \\
\text { ая тревога }\end{array}$} & \multicolumn{2}{c|}{$\begin{array}{c}\text { Выраженная } \\
\text { тревога }\end{array}$} \\
\cline { 2 - 10 } & абс & $\%$ & Абс & $\%$ & абс & $\%$ & Абс & $\%$ \\
\hline Общ.кол. & 12 & 41,4 & 7 & 30,4 & 4 & 17,4 & - & - \\
\hline Детский & 2 & 8,7 & 2 & 8,7 & - & - & - & - \\
\hline Молодой & 10 & 43,5 & 5 & 21,7 & 4 & 17,4 & - & - \\
\hline Средний & - & - & - & - & - & - & - & - \\
\hline
\end{tabular}

Сравнивая по степеням выраженности возможная тревога наблюдалась в 1,2 раза чаще, чем при мигренозном статусе, и в 2,5 раза реже, чем при хронической мигрени. Тревога в отличие от возможной тревоги встречалась в 1,4 раза чаще при мигренозном статусе, и в 1,5 раза чаще при хронической мигрени. Симптоматическую тревогу наблюдали практически одинаково с мигренозным статусом, и в 1,6 раза чаще, чем при хронической мигрени.

Из описанного следует, что хроническая и эпизодическая головная боль, проявляющаяся при мигрени может стать причиной развития депрессии и тревоги, которые коррелируют с интенсивностью, длительностью и частотой субъективных ощущений боли как при осложненных, так и при неосложненных вариантах его клинического течения, с той лишь разницей, что в отличие от неосложненных форм, при осложненных формах мигрени они могут быть более стойкими и выраженными.

\section{Выводы:}

1) Основные субъективные симптомы мигрени по опроснику ID-migraine как осложненных, так и неосложненных форм заболевания могут проявляться одинаково;

2) Психопатологические состояния могут быть следствием мигренозных приступов и коррелируют их интенсивностью, частотой и длительностью; 
3) Основные субъективные симптомы с сопутствующими психопатологическими состояниями могут определить критерии диагностики осложненных форм мигрени.

\section{Использованная литература}

1) Международная классификация головных болей: Перевод В.В. Осиповой, Т.Г. Вознесенской. - Издание 2-е. - 2003. - 219 с.

2) Свиридова Н.К. Особенности диагностики и лечения головной боли, связанной с приступами мигрени // боль под контролем -2015 №1 (186). с.4-8

3) Справочник по головной боли / Кадыков А.С., Шахпаронова Н.В., Манвелов Л.С. - М.: «Милкош», 2005. - 170 с.

4) Чуйко 3.А. Мигрень//здоровье и успех. - 2004. - № 12. с.6-9

5) Lipton RB, Stewart WF, Diamond S, Diamond ML, Reed M. Prevalence and burden of migraine in the United States: data from the American Migraine Study II. Headache, 2001, 41 (7): 646-57.

6) Marmura M., Silberstein S., Schwedt T. The acute treatment of migraine in adults: the american headache society evidence assessment of migraine pharmacotherapies // Headache. - 2015. - Vol. 55 (1). - P. 3-20.

7) Jaracz J., Gattner K., Moczko J., Hauser J. Comparison of the effects of escitalopram and nortriptyline on painful symptoms in patients with major depression // Gen. Hosp. Psychiatry. - 2015. - Vol. 37 (1). - P. 36-39. 